\title{
Erratum to: The melanin-concentrating hormone-1 receptor modulates alcohol-induced reward and DARPP-32 phosphorylation
}

\author{
Camilla Karlsson ${ }^{1} \cdot$ Faazal Rehman $^{2} \cdot$ Ruslan Damadzic $^{2}$ • Alison L. Atkins ${ }^{1}$ • \\ Jesse R. Schank ${ }^{3}$ - Donald R. Gehlert ${ }^{4} \cdot$ Pia Steensland $^{5} \cdot$ Annika Thorsell $^{1}$ • \\ Markus Heilig ${ }^{1}$
}

Published online: 21 September 2016

(C) Springer-Verlag Berlin Heidelberg 2016

Erratum to: Psychopharmacology 233(12): 2355-2363

DOI 10.1007/s00213-016-4285-y

The original version of this article contained a mistake in the family name of the third author. Correct presentation of the name should be Ruslan Damadzic.

The online version of the original article can be found at doi:http://dx.doi. org/10.1007/s00213-016-4285-y.

Markus Heilig

markus.heilig@liu.se

1 Department of Clinical and Experimental Medicine, Linkopings University, Linkoping, Sweden

2 Laboratory of Clinical and Translational Studies, National Institute on Alcohol Abuse and Alcoholism (NIAAA), National Institutes of Health (NIH), Bethesda, MD, USA

3 Department of Physiology and Pharmacology, University of Georgia, Athens, GA, USA

4 Neuroscience and Endocrine Discovery Research, Lilly Research Laboratories, a Division of Eli Lilly and Company, Indianapolis, IN, USA

5 Department of Clinical Neuroscience, Karolinska Institutet, Stockholm, Sweden 